\title{
ТРОФИЧЕСКАЯ ЯЗВА СОВРЕМЕННОЕ ПРЕДСТАВЛЕНИЕ О ЛЕЧЕНИИ (ОБЗОР)
}

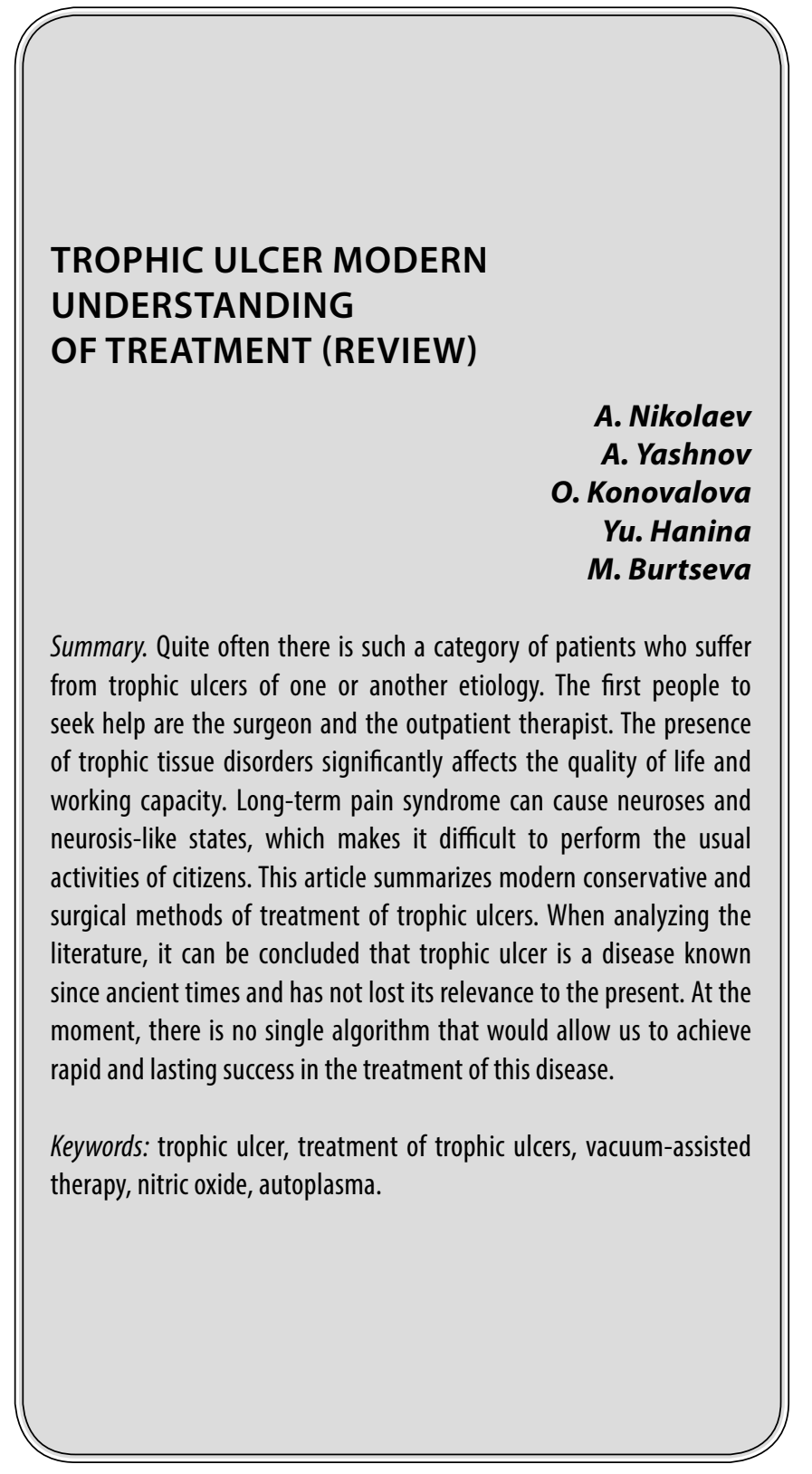

$\mathbf{T}$ рофическая язва - это разновидность длительно незаживающих, устойчивых к консервативному лечению, дефектов кожных покровов, которые характеризуются торпидным и рецидивным течением. Этиологическая частота примерно разделена на: варикозные - 52\%; артериальные - 14\%; смешанные - 13\%; посттромбофлебетические - 7\%; посттравматические - 6\%; диабетические - 5\%; нейротрофические - $1 \%$; и прочие - $2 \%$.
Николаев Алексей Николаевич

ГАУЗ Клинический медицинский чентр г. Чита alexei.nikolaevn@yandex.ru

яшнов Алексей Александрович

ФГБОУ ВО Читинская государственная медицинская академия

Коновалова Ольга Геннадьевна ФГБОУ ВО Читинская государственная медицинская академия

Ханина Юлия Сергеевна

ФГБОУ ВО Читинская государственная медицинская академия

Бурцева Мария Александровна ФГБОУ ВО Читинская государственная медицинская академия

Аннотация. Довольно часто встречается такая категория пациентов, которые страдают трофическими язвами той или иной этиологии. Первые, к кому обращаются за помощью, являются хирург и терапевт амбулаторного звена. Наличие трофических расстройств тканей значительно влияет на качество жизни и трудоспособность. Длительный болевой синдром может вызывать неврозы и неврозоподобные состояния, что затрудняет выполнение привычной деятельности граждан. В данной статье 0бобщены современные консервативные и хирургические методы лечения трофической язвы. При анализе проводимой литературы можно сделать вывод, что трофическая язва — это заболевание известное с давних времен и не потерявшее свою актуальность по настоящее время. В данный момент нет единого алгоритма, который позволил бы добиться быстрого и стойкого успеха в терапии данного заболевания.

Ключевые слова: трофическая язва, лечение трофической язвы, вакуум-ассистированная терапия, оксид азота, аутоплазма.

Первые упоминания о лечении трофических язв, датированные XX-XV веком д.н.э., обнаружены в древнеегипетских папирусах и свитках, которые располагались в Великой Александрийской библиотеке. Фундамент в изучении данной патологии заложили Гиппократ, Авиценна и Чинг Су Вен. Независимо друг от друга данные врачи-ученые отметили взаимосвязь между наличием у больных язв на нижних конечностях и варикозным расширением вен. Вместе с тем, они опи- 
сали и необходимость в ряде лечебных мероприятий: приподнятое положение конечности, ежедневное промывание раны и компрессия давящей повязкой, а также выжигание или перевязка вен, которые подходят к язве. В III веке д.н.э. в трудах древнеиндийских врачей «Сушрута Самхита» описаны и хирургические методы лечения трофических язв с использованием кожной пластики. Последняя выполнялась на дефект кожных покровов, подготовленный путем очищения личинками мясных мушек. Цельс и Гален в лечении трофических язв активно использовали перевязку и экстракцию варикозных вен. Дальнейшее изучения этиологии и лечение трофических язв замедлилось и лишь в XIIIXIV веке н.э. французский хирург Ги Де Шолиак указал на роль этапного лечения язв, которое опиралось на эрадикации патогенных микроорганизмов с наложением вторичных швов и плотного бандажа. В 1676 г. Британский хирург Ричард Вайсман вводит понятие «варикозные язвы» и показывает на значимость эластической компрессии с использованием чулок. Унна в 1854 г. изобрел и с успехом применил «сапожок Унна» (цинк-желатиновую повязку). Гай и Спиндер в 1868 г. доказали роль тромбоза глубоких вен в патогенезе трофических язв. В 1967 г. Амолди и Хагер показали значимость недостаточности перфорантных вен в развитии трофической язвы [1].

До настоящего времени остаётся открытым вопрос лечения трофической язвы. Консервативная терапия зачастую трудоемкая, длительная по времени, слабоэффективная, экономически затратная. У пациентов с трофическими язвами ухудшается качество жизни. Выраженный болевой синдром обрекает пациентов на длительное мучение, нарушение сна, невозможность выполнения привычной повседневной работы. По данным разных авторов данному заболеванию подвержены 1-2\% лиц трудоспособного возраста и до 6-7\% пациентов преклонного возраста, порядком до 2,5 млн. человек в мире имеют нарушение целостности кожных покровов по причине трофических язв в областях стоп и голеней. Язвы, локализованные на нижних конечностях, характеризуются длительным существованием, в ряде случаев на протяжении от 1-10 лет. Так по данным А.Н. Косенкова 45\% больных с трофическими язвами страдали данным заболевание на протяжении более 10 лет. Трофические язва часто протекают с рецидивами. У $35 \%$ пациентов рецидив заболевания наблюдался 3-4 раза. Дискомфорт, выраженные боли, длительное течение трофических язв приводит к смене рода деятельности больных вплоть до потери работы [2].

Помимо социально-бытовых трудностей пациента, лечение трофических язв достаточно затратный метод. В Европе средняя стоимость лечения пациентов с трофическими язвами достигает 40000 евро (око- ло 3,5 млн. рублей). А затраты, которые обусловленные утратой трудоспособности в Германии, достигают 500 млн. евро. При этом необходимо отметить тот факт, что лишь 50\% трофических язв заживают в течении 4 месяцев, 20\% в течении 2 лет, 8\% не закрываются и при 5 летнем лечении [2].

Учитывая то обстоятельство, что продолжительность жизни неуклонно возрастает, происходит и рост числа больных с тяжёлыми формами хронической венозной недостаточности. К первоочередным факторам риска возникновения трофических язв относят: возраст старше 50 лет, избыточная масса тела и урбанизация [2].

До настоящего времени нет единого подхода к лечению трофических язв. В терапии данного заболевания использую как консервативные, так и хирургические методы. К одному из консервативных методов лечения относят использование апитерапевтических средств. В литературе имеются многочисленные данные разнообразного применения пчелиного яда. Последний использовали как при непосредственном ужаливании пчёлами по периферии язв отступя от краёв на 5см, так и с помощью применения мази «Апилак». Апитоксин рекомендуется использовать не только в результате пчёлоужаливания, но и в виде подкожных и внутримышечных инъекций в биологически активные точки. Возможно и применение данного средства при выполнении физиотерапевтических процедур (фоноорез, электрофорез, аппарат Фолля). В результате многочисленных исследований доказано, что апитоксин стимулирует репаративные процессы и повышает процессы рассасывания воспалительного вала вокруг изъязвления [3].

В качестве консервативного метода лечения трофических язв описано и применение оксида азота. А.Н. Плеханов в своем исследовании описывает эффективность использования аппарата «Плазон» в режиме стимулятор-коагулятор на расстоянии 15-20 см от поверхности раны на протяжении 10 минут. В результате данного исследования показано, что применение оксида азота на протяжении 10 сеансов приводит к улучшению микроциркуляции, создаёт дисбаланс между прооксидантной и антиоксидантной системами, стимулирует репаративный процесс [4].

В одном из исследований показано эффективность применения аутологичной плазмы обогащенной лизатом тромбоцитов. В результате данного исследования Исаева Т.Н. показала определенные успехи в заживлении длительно незаживающих язв, в том числе и у лиц с избыточной массой тела. Данный метод основан на том, что при разрушении мембраны тромбоцита в плазме крови появляются факторы роста, которые 
активно стимулируют процессы миграции и пролиферации мезенхимальных стволовых клеток, отвечающих за регенерацию тканей [5]. М.А. Смагин в своём исследовании также показал эффективность использования плазмы, обогащенной тромбоцитами. Им отмечено, что двукратное введение аутологичной плазмы, обогащенной тромбоцитами, ускоряет процессы эпителизации трофической язвы [6].

О роли стволовых клеток в заживлении трофических язв в литературе описано достаточно много. Так Е. Баранов в своей статье описал использование стволовых клеток и светодиодную терапию. В данном научном труде отмечено эффективность комплексного использования локальной фототерапии и ауто-ММСК жировой ткани и установлено, что данная терапия обладает способностью ускорять процессы регенерации [7].

Немаловажным в лечении трофических язв отдаётся местному применению мазевых повязок с использованием в составе мазей компонентов, способствующих регенерации. К таким мазям относят: «Метиурациловая», «Офломелид», «Солкосерил», «Пантенол» и другие. Помимо использования мазевых повязок, свою эффективность показали и повязки на гидрогелиевой основе [8].

Наряду с местным применением лекарственных средств немаловажная роль отводится и методам применения компрессии. По данным полученным Маслаковой Н.Д., можно судить о эффективности использования модифицированной повязки Унна. В эксперименте доказано, что данный метод значительно сокращает сроки лечения с сохранением физической активности пациентов. Повязка Унна способствует созданию комфортной влажности и температуры кожных покровов, препятствуя проникновению инфекции [9].

Немаловажное значение в лечении трофической язвы отводится использованию вакуум-ассистирован- ной терапии. И. Чумбуридзе в своей работе показал высокую лечебную роль вакуум терапии с использованием аппарата Vivano NPWT System с прерывистым режимом рабочего давления 125 мм.рт.ст. в течении 5 минут и 20 мм.рт.ст в течении 2 минут. Данное исследование показало, что вакуум-асситированная терапия трофической язвы позволяет добиться более быстрого очищения раны и способствует ускоренной грануляции [10].

Среди хирургических вмешательств наиболее часто используется хирургическая обработка раны с некрэктомией путём соскабливания или воздействием водоструйным скальпелем. Помимо очищения раны, ряд авторов при трофических язвах, вызванных хронической венозной недостаточностью, советуют воздействовать и на звенья этиопатогенеза данного заболевания. Так О.С. Попов в своей работе предлагает при поверхностных малых трофических язвах ограничится эндоскопической диссекцией перфорантных вен, а у пациентов с обширными ранами после подготовки поверхности использовать аутодермопластику [11].

Все методы терапии трофических язв, по нашему мнению, можно условно поделить на 3 группы:

1 группа - местные на рану: некрэктомия, использование мазей, применение озона, вакуум-ассистированная терапия и др.;

2 группа - компрессионная терапия: эластическая компрессия, сапожок Унна и др.;

3 группа - хирургические: венэктомия, аутодермопластика.

При анализе проводимой литературы можно сделать вывод, что трофическая язва достаточно сложное заболевание, которое плохо поддаётся лечению. В настоящее время нет единого алгоритма, который позволил бы добиться быстрого и стойкого успеха в терапии данного заболевания. Все перечисленные методы дают хороший результат при использовании в различных комбинациях.

\section{ЛИТЕРАТУРА}

1. Савельев В.С. Флебология. Руководство для врачей. - М.-2001.-523с.

2. Довнар В.И. Трофичсекие язвы: современные аспекты этиологии и патогенеза. Журнал ГРГМУ.— 2009.— № 4. — С. 3-6.

3. Дударев С.В. Приминение апитоксина в лечении трофических язв. Научный альманах. - 2018. — № 12-2.—C. 88-95.

4. Плеханов А.Н. Патогенетическое значение оксида азота в лечении обширных диабетических трофических язв. Вестник Бурятского Государственного университета (Медицина и Фармацея). — 2018. - № 3-4.—C. 62-65.

5. Исаева Т.Н. Результаты лечения трофических язв различного генеза и локализации с помощью аутологичной плазмы обогащенной лизатом тромбоцитов. Гены и Клетки.— 2017.—- Т. 12. № 3.—С. 106-107.

6. Смагин М.А. Алгоритм лечения трофических язв у пациента с сахарным диабетом на фоне хронической ишемии нижних конечностей. В книге: Лимфология: от фундаментальных исследований к медицинским технологиям. Материалы XIII международной научно-практической конференции памяти академика Ю.И. Бородина.—2018.—C. 119-120. 
7. Баранов Е. Лечение трофических язв с использованием светодиодной фототерапии стволовых клеток. Наука и инновации. — 2019. — № 2(192). C. $70-75$.

8. Жуков А.А. Варианты комплексного лечения пациентов с венозными трофическими язвами. В сборнике: Харизма моей хирургии. Материалы Всероссийской конференции с международным участием, посвященная 160-летию ГБКУЗ Я0 «Городская больница им Семашко». Под редакцией А.Б. Ларичева.- 2018.- С. 400-403.

9. Маслакова Н.Д. Опыт применения компрессионной повязки в лечении трофических язв нижних конечностей. В сборнике: Современные технологии в хирургической практике. Сборник материалов Республиканской научно-практической конференции под редакцией В.А. Снежицкий. - 2017.— C. 131-133.

10. Чумбуридзе И. Вакуум-ассистированная терапия трофических язв венозной этиологии. Врач. — 2016. — № 7. — С. 46-48.

11. Попов 0.С. Комбинированный хирургический метод лечения венозных трофических язв нижних конечностей. Креативная хирургия и онкология.2011. - № 1.—C. 74-77.

( ) Николаев Алексей Николаевич ( alexei.nikolaevn@yandex.ru ), Яшнов Алексей Александрович,

Коновалова Ольга Геннадьевна, Ханина Юлия Сергеевна, Бурцева Мария Александровна.

Журнал «Современная наука: актуальные проблемы теории и практики»

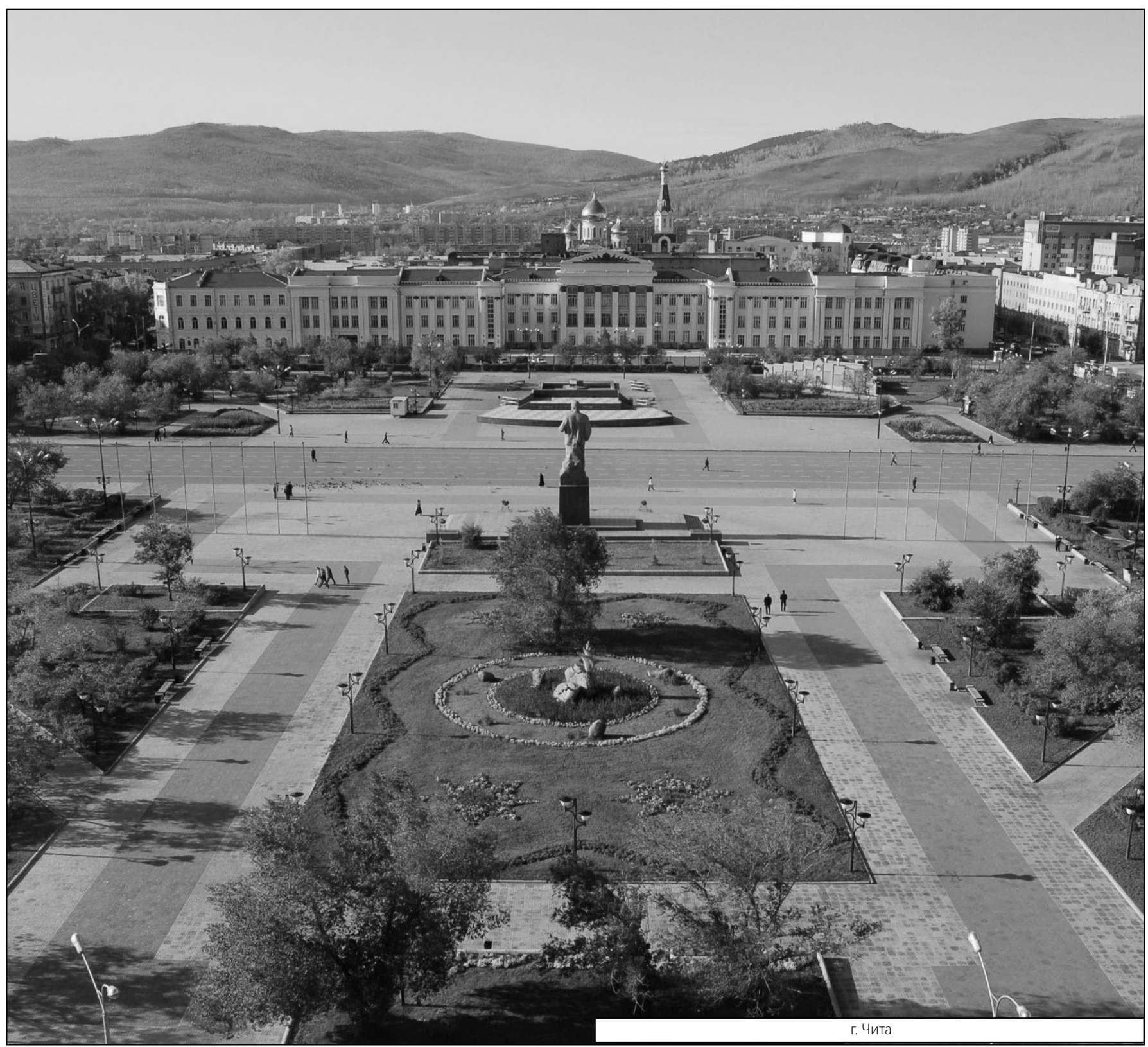

